\title{
PROPERTIES OF LIGNIN MICROPARTICLES PREPARED BY MECHANICAL TREATMENT
}

\author{
DANIELLY DE OLIVEIRA BEGALI, ANA CAROLINA SALGADO DE OLIVEIRA, \\ LAURA FONSECA FERREIRA, ${ }^{*}$ CASSIANO RODRIGUES DE OLIVEIRA, \\ LUIS ROBERTO BATISTA, ${ }^{*}$ ODÍLIO BENEDITO GARRIDO DE ASSIS, ${ }^{* *}$ \\ MARIA IRENE YOSHIDA**** and SORAIA VILELA BORGES ${ }^{*}$ \\ "Food Science Department, Federal University of Lavras, Lavras, Minas Gerais, Brazil \\ *** Institute of Exact and Technological Sciences, Federal University of Viçosa, \\ Rio Paranaiba, Minas Gerais, Brazil \\ ****Embrapa Instrumentation, São Carlos, São Paulo, Brazil \\ **** Department of Chemistry, Federal University of Minas Gerais, \\ Belo Horizonte, Minas Gerais, Brazil \\ \orresponding author: D. de Oliveira Begali, danibegali@gmail.com
}

Received October 16, 2020

\begin{abstract}
The present study aimed to obtain Kraft lignin microparticles by mechanical treatment and compare them with initial Kraft lignin in terms of their chemical, thermal and structural properties, as well as possible antioxidant and antimicrobial effects. Ball milling reduced the particle size from $6.6 \mu \mathrm{m}$ to $3.1 \mu \mathrm{m}$. The zeta potential and polydispersity index measurements revealed greater instability of the microparticles, with a higher tendency to agglomerate, and higher homogeneity, when compared with Kraft lignin. These findings were also evidenced by scanning electron microscopy. The thermal degradation behavior was not affected by the mechanical treatment utilized in the production of microparticles. X-ray diffraction showed crystalline and amorphous regions in the particles. Infrared spectroscopy revealed that the microparticles maintained the characteristic peaks of Kraft lignin, with lower peak intensity. The samples proved high antioxidant potential, as determined by the 2,2-diphenyl-1-picryl-hydrazyl assay, regardless of the concentration studied. Therefore, the results of the study demonstrated that the obtained Kraft lignin microparticles could be suitable for the development of antioxidant food packaging.
\end{abstract}

Keywords: lignin, milling, waste, antioxidant property, particles

\section{INTRODUCTION}

Lignin is a highly cross-linked threedimensional macromolecule, responsible for providing structural strength and protection to plants. It is found in large quantities as a byproduct in the pulp and paper industry and in the production of ethanol from lignocellulosic biomass. ${ }^{1-3}$

Lignin has a complex chemical structure, consisting of several units of phenylpropane with the formation of three aromatic alcohols, such as $\rho$-coumaryl ( $\rho$-hydroxyphenyl, $\mathrm{H})$, coniferyl (guaiacyl, S) and sinapyl alcohols (syringyl, S). ${ }^{2,45}$ Its chemical structure depends on a number of factors, including its botanical origin, environmental conditions, and extraction techniques. All delignification techniques involve cleaving the covalent bonds from natural lignin, resulting in the solubilization of polymer fragments. Lignin can have different antioxidant and antimicrobial activities as a function of the extraction conditions used (temperature and solvent/residue rate), ${ }^{4,6}$

Various techniques for obtaining nano- and microparticles have been studied to improve the availability of the active compounds of lignin. Yang et $\mathrm{al}^{7}$ studied the valorization of acid isolated high yield lignin nanoparticles as an innovative antioxidant/antimicrobial organic material and concluded that the extraction procedure was effective for the antioxidant and antimicrobial effect.

Studies have shown that smaller particles are more available for the reaction, and exhibit improved dispersion. ${ }^{4,7}$ In addition, particle size 
reduction can offer more bioactive compounds and potentially substitute for synthetic products in food or cosmetics. ${ }^{8,9}$ Moreover, when using smaller size fillers, better interactions with other materials are observed, for example, polymers, in the production of polymer blends for the production of biodegradable and active packaging. ${ }^{10}$

There are a lot of studies on the development of lignin nano- and microparticles, each using different solvents and obtaining methods. As examples, precipitation with ethylene glycol, ${ }^{11}$ tetrahydrofurans (THF) and ethylene glycol as solvent, ${ }^{12}$ enzymatic degradation, ${ }^{13}$ and dissolution with ethylene glycol and different acids. ${ }^{14}$ However, there are few studies about the reduction of particle size by physical methods, with emphasis on high shear homogenization ${ }^{15}$ and ultrasonic irradiation. ${ }^{8,16}$

The present study aimed to produce Kraft lignin microparticles by the milling process, and compare it with unmodified Kraft lignin. Then, the chemical, thermal and structural properties, as well as antioxidant and antimicrobial effects, were investigated in view of a prospective use of the obtained material in active antioxidant and antimicrobial packaging.

\section{EXPERIMENTAL \\ Material}

Lignin isolated from Kraft black liquor was kindly donated by the Laboratory of Development of Bioactive Products and Technological Solutions of the Federal University of Viçosa (Campus Rio Paranaíba). Methanol was purchased from Vetec; 2,2-diphenyl-1picryl-hydrazyl (DPPH) from Sigma Aldrich. Agar Mueller Hinton (Kasvi, Pinhails, PR, Brazil), Brain Heart Infusion broth (BHI, HiMedia Laboratories Pvt. Ltd., Mumbai, India), Tryptic Soy broth (TSB, HiMedia Laboratories Pvt. Ltd., Mumbai, India) and qualitative filter paper (Qualy) were purchased from different companies in Brazil.

\section{Obtaining the microparticles}

A ball mill with a video camera (model TE-350, Tecnal - São Paulo, Brazil) was utilized to produce the microparticles. For that, $10 \mathrm{~g}$ of the sample was placed in an enclosed container, together with steel balls, attached to the equipment. The sample was subjected to grinding for 2 minutes and the procedure was repeated 3 times to obtain the lignin microparticles.

\section{Characterization of the microparticles \\ Scanning electron microscopy (SEM)}

The morphological analysis was carried out by scanning electron microscopy (SEM), using a LEO
EVO 40 XVP microscope (Zeiss, Cambridge, England), with an acceleration voltage of $18.59 \mathrm{kV}$. The powder samples were mounted on aluminum stubs, using double-coated carbon, and coated by gold plating under vacuum metallization.

\section{$X$-ray diffraction $(X R D)$}

The X-ray diffraction of the powder was carried out in a Shimadzu XRD-6000 (Kyoto, Japan) diffractometer with $\mathrm{Cu}-\mathrm{K} \alpha$ filter radiation $(\lambda=1.5406$ $\AA ̊$ ), operating at $30 \mathrm{kV}$ and $30 \mathrm{~mA}$. The samples were fixed in an aluminum support and analyzed at a scanning rate of $2 \% \mathrm{~min}$, with $2 \theta$ ranging from 4 to $70^{\circ}$ at room temperature. The curves were analyzed using Origin ${ }^{\circledR} 8.5$ software and the relative crystallinity index $(\mathrm{CI})$ of the samples was calculated according to Equation 1: ${ }^{17}$

Icr $=(H c /(H c+H a)) \times 100$

where $\mathrm{Icr}$ is the crystallinity index (\%), $\mathrm{Ha}$ is the height corresponding to the amorphous phase in relation to the baseline, and $H c$ is the height corresponding to the crystalline peak.

\section{Particle size, zeta potential, and polydispersity index}

The determinations were carried out in triplicate, using a Zeta Potential Analyzer model ZS 3600 from Malvern Instruments (Worcestershire, UK). The equipment allows determining the particle size by the dynamic light scattering technique. The instrument is capable of measuring the electrical charge resulting from the interaction of a material with a given liquid. The zeta potential measurement is expressed in $\mathrm{mV}$ units, with an average of 5 readings. The polydispersity index provides information on the homogeneity of the particle size distribution.

\section{Fourier transform infrared spectroscopy (FTIR)}

Fourier transform infrared spectroscopy (FTIR) was utilized to obtain information on the functional groups present in the samples. FTIR analyses were carried out on a JASCO FT-IR 4100 Spectrometer (Tokyo, Japan), using attenuated total reflectance (ATR) with a diamond crystal. 256 scans were performed in the spectral range from 4000 to $400 \mathrm{~cm}^{-1}$, at $1 \mathrm{~cm}^{-1}$ resolution.

\section{Thermogravimetric analysis (TGA)}

The thermal stability of the lignin microparticles was determined by thermogravimetric analysis (TGA) using DTG60H-SHIMADZU apparatus (Kyoto, Japan). The analysis was carried out under a nitrogen atmosphere, with a flow rate of $50 \mathrm{~mL} / \mathrm{min}$, heating from 50 to $600{ }^{\circ} \mathrm{C}$, at a heating rate of $10^{\circ} \mathrm{C} / \mathrm{min}$.

\section{Antioxidant activity}

The antioxidant potential of the samples was determined using the 2,2-diphenyl-1-picryl-hydrazyl (DPPH) free radical capture method. For that, solutions 
of $1 \%, 2 \%, 4 \%$ and $6 \%$ lignin microparticles were prepared in $80 \%$ methanol solution. The analysis was carried out in triplicate. The mixture was vortexed for $3 \mathrm{~min}$ and allowed to rest at room temperature for $3 \mathrm{~h}$. Then, the mixtures were vortexed again for $3 \mathrm{~min}$. An aliquot of the lignin microparticles methanol extract (sample) was mixed with $3.9 \mathrm{~mL}$ of $0.1 \mathrm{mM}$ DPPH in $80 \%$ methanol. The mixture was vortexed for $1 \mathrm{~min}$ and allowed to rest in the dark for $30 \mathrm{~min}$ or $60 \mathrm{~min}$. Absorbance was measured at $517 \mathrm{~nm}$ using a spectrometer (SP 2000UV). A solution with $0.1 \mathrm{mM}$ DPPH in $80 \%$ methanol was utilized as a control. The radical scavenging activity (RSA) was calculated according to Equation $2:^{18}$

$\operatorname{RSA}(\%)=(($ A sample $-A$ control $) / A$ control $) \cdot 100$

where A control: absorbance of the DPPH solution; $A$ sample: absorbance of the sample with DPPH.

\section{Antimicrobial activity}

Solution of lignin microparticles in DMSO

Solutions of Kraft lignin microparticles were prepared with concentrations of $1 \%, 2 \%, 4 \%$ and $6 \%$ $(\mathrm{m} / \mathrm{v})$ in DMSO (dimethyl sulfoxide) for the analysis.

\section{Microorganisms and growth conditions}

Bacterial strains of Escherichia coli (EPEP055) and Staphylococcus aureus (ATCC13565) were utilized in the study.

The bacterial strains (mother strains) were stored in a medium containing glycerol $(15 \%)$, peptone $\left(5 \mathrm{~g} \mathrm{~L}^{-1}\right)$, yeast extract $\left(3 \mathrm{~g} \mathrm{~L}^{-1}\right), \mathrm{NaCl}\left(5 \mathrm{~g} \mathrm{~L}^{-1}\right)$, at $\mathrm{pH} 7.2 \pm 7.4$ and $-4{ }^{\circ} \mathrm{C}$. The strains were activated in $5 \mathrm{~mL}$ of Brain Heart Infusion broth and incubated at $37{ }^{\circ} \mathrm{C}$ for 24 hours. After activation, an aliquot was transferred to a tube containing Tryptic Soy broth until reaching the reference turbidity of a 0.5 McFarland standard solution, resulting in a bacterial suspension with $10^{8}$ CFU $\mathrm{mL}^{-1}$. The turbidity was adjusted in the range from 0.08 to $0.1 \AA$, using a spectrophotometer (Shimadzu UV-160 $1 \mathrm{PC}$, Japan) at $625 \mathrm{~nm} .{ }^{19}$

\section{Agar diffusion test}

The agar disk-diffusion test was carried out according to the Kirby-Bauer method, using the performance standards M2-A8 of NCCLS, ${ }^{19}$ and M38A of NCCLS, ${ }^{20}$ for bacteria and fungi, respectively. The tests were carried out in triplicate.

To assess the antibacterial effect, $100 \mu \mathrm{L}$ of the inoculum $\left(10^{8} \mathrm{CFU} \mathrm{mL} \mathrm{m}^{-1}\right)$ was spread with the aid of a Drigalski loop on the surface of a plate containing Mueller Hinton Agar. Filter paper discs $(5 \mathrm{~mm}$ in diameter) were placed on the surface and $10 \mu \mathrm{L}$ of the lignin microparticle suspension with concentrations of $1 \%, 2 \%, 4 \%$ and $6 \%$ was added to the discs. The plates were incubated in an incubation chamber at $37{ }^{\circ} \mathrm{C}$ for 24 hours. After this period, the zone of inhibition surrounding the microbial discs was analyzed, and the inhibition halo was measured.

\section{RESULTS AND DISCUSSION Scanning electron microscopy (SEM)}

Figures $1 \mathrm{~A}$ and $1 \mathrm{~B}$ show micrographs of Kraft lignin, while Figures 1C-D present the lignin microparticles. Figures 1A-B reveal the heterogeneity of the lignin sample size, and it is possible to observe some agglomerates. On the other hand, Figures 1C and 1D reveal a more homogeneous material, with micro-scale particles rather than nanoparticles. Despite having more uniform particles, the presence of agglomerates in some spots is observed, which contributes to irregularities in particle size.

Thus, it can be concluded that the mechanical action (milling process) applied to the sample was sufficient to reduce the particle size. In addition, both Kraft lignin and Kraft lignin microparticles exhibited irregular distribution in shape and size. To verify these findings, the particle size, zeta potential and the polydispersion index were analyzed.

Gomide et $a l .^{8}$ also observed a decrease in particle size after the application of a sonication treatment. Yang et al. ${ }^{14}$ obtained similar results, but used ethylene glycol, followed by the addition of different acidic conditions.

\section{X-ray diffraction}

The XRD analysis was performed to better understand the morphology of the lignin, identifying the crystalline and amorphous phases present in the sample. Furthermore, this analysis was performed to verify if any changes occurred in the structure after the milling process. ${ }^{8,13}$

Figure 2 shows the diffractograms of Kraft lignin and lignin microparticles, showing the presence of amorphous regions and peaks indicating crystalline regions. Crystalline regions are not characteristic of the lignin structure, because of its amorphous nature. This indicates the presence of inorganic material, as suspected further in the TG analysis, due to high percentages of residues. Kraft lignin has higher or lower intensity peaks than Kraft lignin microparticles. This variation in peak intensity is due to changes in the crystal structure occurring during milling to obtain the microparticles, which led to the rupture of crystalline areas and the formation of modified crystalline domains. ${ }^{13}$ 

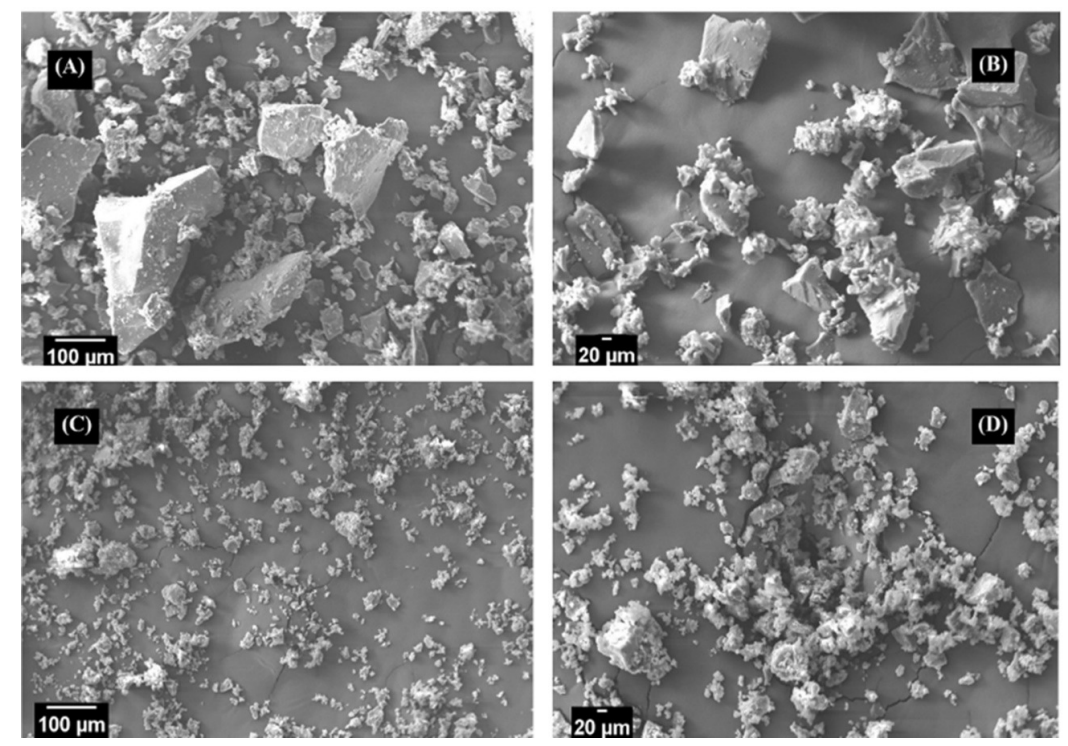

Figure 1: Scanning electron micrographs of Kraft lignin (A and B) and Kraft lignin microparticles (C and D)

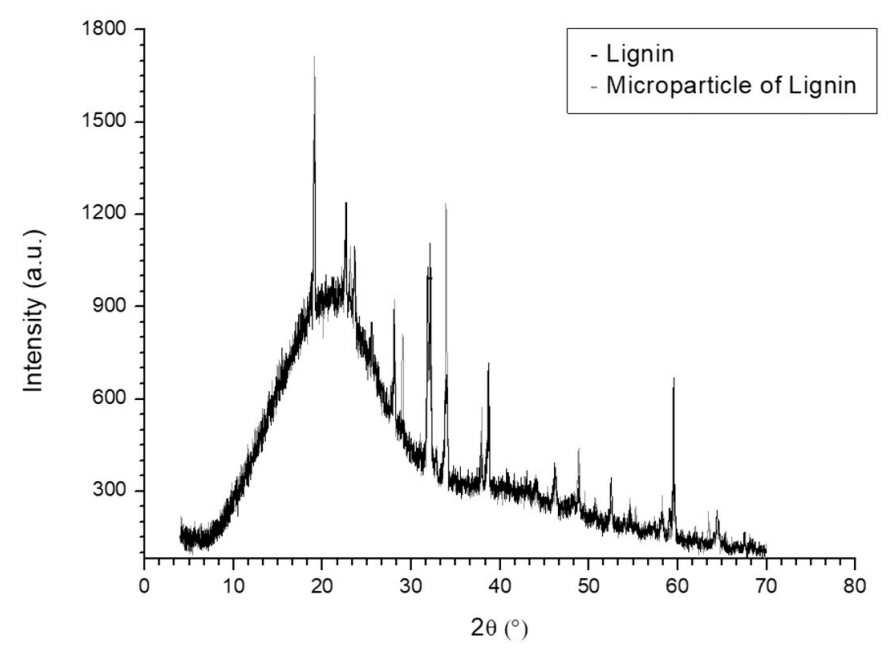

Figure 2: Diffractograms of Kraft lignin and Kraft lignin microparticles

Table 1

Zeta potential, polydispersity index (PDI), particle size of Kraft lignin and Kraft lignin microparticles

\begin{tabular}{lccc}
\hline Samples & $\begin{array}{c}\text { Zeta potential } \\
(\mathrm{mV})\end{array}$ & PDI & $\begin{array}{c}\text { Particle size } \\
(\mu \mathrm{m})\end{array}$ \\
\hline Kraft lignin & $-20.5 \pm 0.12$ & $0.841 \pm 0.13$ & $6.567 \pm 0.15$ \\
Kraft lignin microparticles & $4.01 \pm 0.77$ & $0.580 \pm 0.24$ & $3.097 \pm 0.47$ \\
\hline
\end{tabular}

Concerning the crystallinity index, the Kraft lignin presented $16 \%$ crystallinity index and $84 \%$ amorphous halo, with the maximum diffraction intensity of 933 at $2 \theta=33.89^{\circ}$ and a minimum intensity of 89.95 at $2 \theta=48.28^{\circ}$. In contrast, the lignin microparticles presented $15.6 \%$ crystallinity index and $84.4 \%$ amorphous halo, with a maximum intensity of 746.78 at $2 \theta=32^{\circ}$ and a minimum intensity of 89.95 at $2 \theta=48.87^{\circ}$. These results demonstrate that the mechanical treatment used to produce the microparticles did not affect the samples' crystallinity.

Luo et $a .^{21}$ and Rangam et al. ${ }^{13}$ reported that lignin is glassy and has little or no crystalline 
structure due to its complex structural network between functional groups. This statement corroborates the present results, where the highest percentage is found in the amorphous halo in both samples.

\section{Particle size, zeta potential, and polydispersity index}

As shown in Table 1, although the particle size of the Kraft lignin subjected to mechanical treatment reduced by more than $50 \%$, it did not reach the nanoscale, since the size must be $\leq 100$ $\mathrm{nm}(0.1 \mu \mathrm{m})$ to be considered a nanoparticle.

The zeta potential is a measure of the electrical charge of the material that covers the particles, being an indicator of the stability of the suspended nanoparticles. Values above $+30 \mathrm{mV}$ or below $-30 \mathrm{mV}$ indicate a greater electrostatic repulsion between the particles, increasing the particle stability, due to the higher electrical charge. Thus, the repulsion effect prevents the formation of possible clusters. ${ }^{22}$ However, the values found for Kraft lignin, and the microparticles of Kraft lignin (Table 1) are between $-30 \mathrm{mV}$ and $+30 \mathrm{mV}$, indicating electrostatic attraction that causes agglomeration of suspended particles and greater instability of the aqueous solution at $\mathrm{pH} 2.0$.

Liu et $\mathrm{al}^{23}$ reported that the negative zeta potential value of Kraft lignin is partly due to the negative charges of the phenol groups present in the molecule and also the adsorption of hydroxyl ions onto its hydrophobic surface. Thus, the negative surface charge can electrostatically stabilize the lignin particles, preventing particle aggregation.

Considering the values recorded, it is observed that the microparticles obtained a zeta potential value closer to zero, indicating greater electrostatic attraction in relation to the Kraft lignin sample, that is, they are therefore more stable. It is suspected that this is due to the applied energy in the mechanical action, which, by reducing the size of particles, probably increased the specific surface area, causing the redistribution of negative charges and, consequently, promoting agglomerations.

Yang et al. ${ }^{14}$ obtained nanoparticles with zeta potential below $-30 \mathrm{mV}$. The authors stressed that this is justified by the high number of phenolic portions that undergo an electron transfer mechanism coupled to protons, that is, the high density of oxygenated groups on the surface of the lignin particles. In this way, it can be suspected that the Kraft lignin analyzed here has a low density of phenolic portions, thus not promoting this reaction.

The polydispersity index of the particles was evaluated, which measures the relative degree of spread in relation to the particle size distribution of a given sample. The value varies on a scale of 0 to 1 and the lower the value the more monodispersed and less heterogeneous is the sample. ${ }^{24}$ Therefore, even with high instability and a tendency to agglomerate, the microparticles were more uniform in mean size and distribution, compared to Kraft lignin, which exhibited a dispersion index closer to 1 (Table 1). These results corroborate the micrographs shown in Figure 1.

\section{Fourier transform Infrared spectroscopy (FTIR)}

Figure 3 shows the FTIR spectra of Kraft lignin and lignin microparticles. Similar spectra are observed, with differences only in the band intensity, since the Kraft lignin exhibits more intense peaks, when compared to the microparticles. The similarity between the samples indicates small changes in the chemical structure after the milling process.

The spectra of both lignins were similar to those reported in other studies, with the wavenumber $3393 \mathrm{~cm}^{-1}$ referring to the hydroxyl group in aromatic structures, as observed for phenolic compounds involving hydrogen bonds. The bands at $2934 \mathrm{~cm}^{-1}, 2839 \mathrm{~cm}^{-1}$ and $1456 \mathrm{~cm}^{-1}$ correspond to the $\mathrm{C}-\mathrm{H}$ from methoxy, methyl, or methylene groups of the aromatic side chains, indicating branches in the lignin structure. The vibrations of the aromatic rings of both lignin samples were identified at $1599 \mathrm{~cm}^{-1}, 1516 \mathrm{~cm}^{-1}$ and $1419 \mathrm{~cm}^{-1}$. The band at $1718 \mathrm{~cm}^{-1}$ corresponds to the vibrations of $\mathrm{C}=\mathrm{O}$ bonds of the carboxylic groups. The bands at the wavenumbers of $1325 \mathrm{~cm}^{-1}, 1206 \mathrm{~cm}^{-1}, 1110 \mathrm{~cm}^{-1}$ and $1027 \mathrm{~cm}^{-1}$ were associated with the vibrations of the aromatic rings from syringyl and guaiacyl. The band at $824 \mathrm{~cm}^{-1}$ was indicative of the presence of $\mathrm{C}-\mathrm{H}$ deformation vibrations in the aromatic rings. ${ }^{1,14,25}$

\section{Thermal behaviour}

The thermogravimetric curves shown in Figure 4 demonstrate the thermal behaviour of the samples subjected to a given temperature under $\mathrm{N}_{2}$ atmosphere. It is observed that both samples undergo a mass loss of approximately $40 \%$ (Table 
DANIELLY DE OLIVEIRA BEGALI et al.

2), whith the maximum peak mass loss of Kraft lignin around $356{ }^{\circ} \mathrm{C}$ and for Kraft lignin microparticles - at $351{ }^{\circ} \mathrm{C}$ (Fig. 4). Three degradation stages are observed in both lignin samples: I) maximum temperature of $47^{\circ} \mathrm{C}$ to 141 ${ }^{\circ} \mathrm{C}$ related to water loss, that is, sample dehydration; II) maximum temperature around $228{ }^{\circ} \mathrm{C}$, showing hemicellulose and cellulose degradation; III) maximum temperature around $356{ }^{\circ} \mathrm{C}$, corresponding to the degradation process of lignin. ${ }^{14,26}$

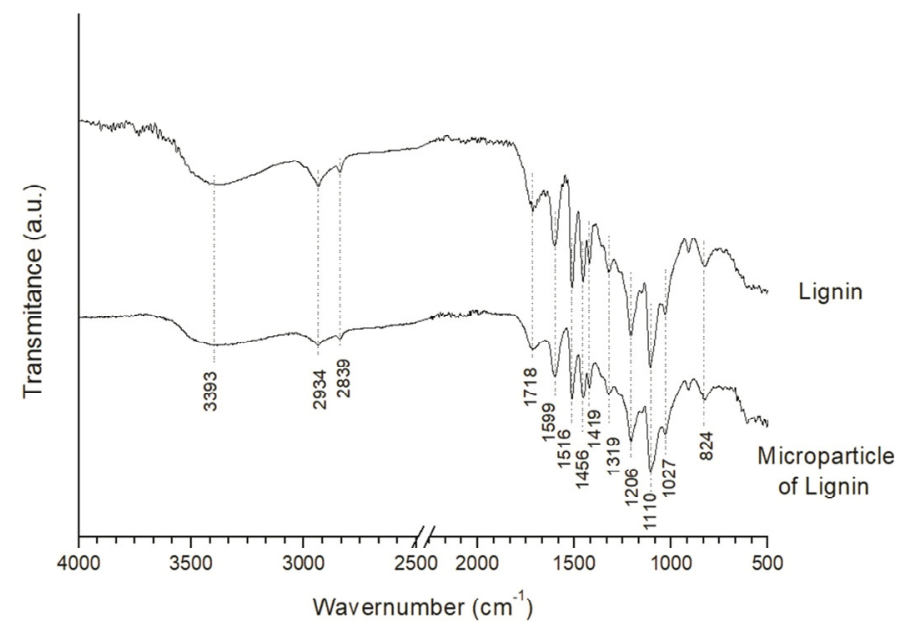

Figure 3: FTIR spectra of Kraft lignin and Kraft lignin microparticles
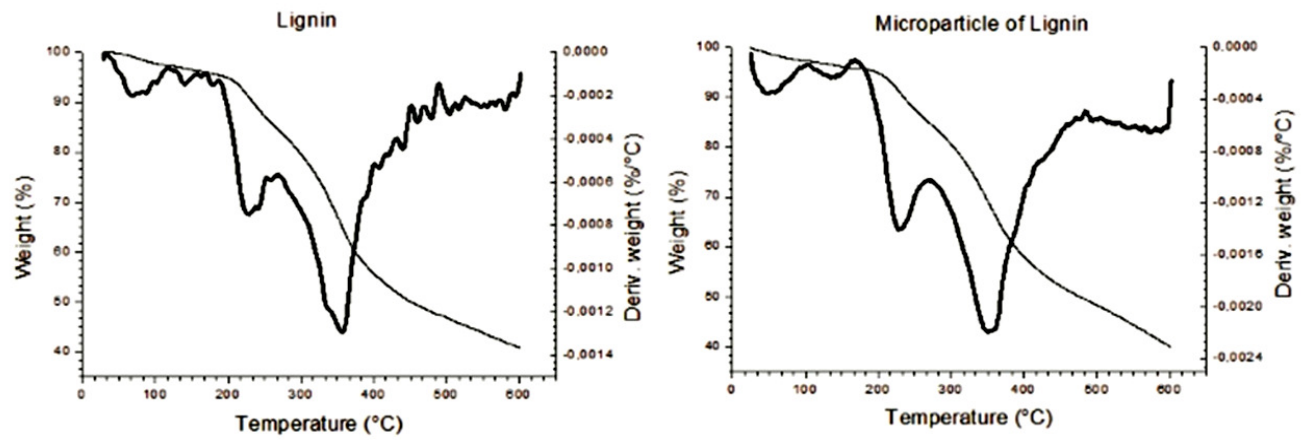

Figure 4: Thermogravimetric analysis of Kraft lignin and Kraft lignin microparticles

Table 2

Thermal parameters of Kraft lignin and Kraft lignin microparticles

\begin{tabular}{|c|c|c|c|c|c|c|c|c|c|}
\hline \multirow[t]{2}{*}{ Samples } & \multicolumn{4}{|c|}{$\begin{array}{c}\operatorname{Tmax} \\
\left({ }^{\circ} \mathrm{C}\right)\end{array}$} & \multicolumn{4}{|c|}{$\begin{array}{c}\text { Mass loss } \\
(\%)\end{array}$} & $\begin{array}{l}\text { Residual mass } \\
\text { at } 600^{\circ} \mathrm{C}(\%)\end{array}$ \\
\hline & $\mathrm{Tp}_{1}$ & $\mathrm{Tp}_{2}$ & $\mathrm{Tp}_{3}$ & $\mathrm{Tp}_{4}$ & $\mathrm{P}_{1}$ & $\mathrm{P}_{2}$ & $\mathrm{P}_{3}$ & $\mathrm{P}_{4}$ & \\
\hline Kraft lignin & 68.58 & 140.95 & 227.83 & 356.06 & 0.8 & 3.15 & 8.81 & 34.78 & 40.83 \\
\hline Lignin microparticles & 47.00 & 136.37 & 228.52 & 351.39 & 1.07 & 3.47 & 8.84 & 31.17 & 39.98 \\
\hline
\end{tabular}

Tmax: Maximum temperature; Tp: Peak temperature; P: Peak

These thermal events were also observed by other authors, such as Chen et al., ${ }^{1}$ who extracted lignin from Miscanthus sinensis; Garcia et al., ${ }^{25}$ who studied black liquor lignin for biofuel; and
Yang et al., ${ }^{14}$ who studied the production of alkaline lignin nanoparticles under different $\mathrm{pH}$ conditions. However, small differences in the temperature range of the thermal degradation 
stages were observed in those studies, when compared to the present work. Chen et al. ${ }^{1}$ also studied Kraft lignin and reported a mass loss of $44.46 \%$, which is close to the result obtained in this study. Garcia et al..$^{25}$ studied the degradation of alkaline lignin and organosolv lignin and reported a mass loss of $20-25 \%$ and $30-40 \%$, respectively. The authors stated that the maximum loss depends on several factors, including the structure of the lignin, the functional groups, the bonds, the origin, and the treatments applied.

Small differences were observed for the lignin samples of the different treatments. The residue from the thermal degradation is also related to the complexity of the structures of the lignin molecules and their degree of bonding. In addition, a high percentage of residual mass may indicate the presence of inorganic matter in the lignin, which may have led to the formation of peaks in the XRD patterns (Fig. 2), since the structure of the lignin is practically amorphous, with no characteristic peaks of crystalline regions. ${ }^{25,27}$ Therefore, high percentages of residues imply high thermal stability of the sample, which is a complex three-dimensional structure, and the presence of contaminants, indicating impurities in the lignin sample analyzed.

The thermal degradation was not affected by the mechanical treatment used for the production of microparticles, once similar results were observed for both samples.

\section{Antioxidant activity}

Lignin has been studied as a potential antioxidant agent, due to the presence of aromatic rings in its chemical structure. These functional groups act through the donation of hydrogen, reducing or even preventing oxidation in foods with high lipid content, i.e., slowing down the formation of free radicals.
As shown in Table 3, the sample with the concentration of $6 \%$ recorded the highest antioxidant activity among all the lignin microparticle samples at a resting time of 30 minutes. However, at 60 minutes, there was a sharp reduction in its antioxidant activity, and similar results were reached for the lignin microparticle concentrations of $2 \%, 4 \%$ and $6 \%$. However, an antioxidant effect was observed for all the solutions of lignin microparticles studied here, regardless of their concentration and resting time.

Similar results were found by Yang et al..$^{14}$ and García et al., ${ }^{25}$ who investigated nanoparticles of alkaline lignin, organosolv lignin and soda lignin. In contrast, some authors reported lower antioxidant activity than those found in this study: for example, Kaur, Uppal and Sharmar ${ }^{9}$ for modified lignin; Garcia et al. ${ }^{27}$ for alkaline and organosolv lignins; and Bertolo et $a .^{26}$ for alkaline lignin nanoparticles, probably because of the method utilized to determine the antioxidant activity. In addition, the first two studies evaluated lignin in other forms than micro- or nanoparticles, which may have led to the differences in the results when compared to the present study.

\section{Antimicrobial activity}

The diffusion disc test was carried out for the solutions of Kraft lignin and Kraft lignin microparticles at concentrations of 10,20, 40 and $60 \mathrm{mg} / \mathrm{mL}$ in dimethyl sulfoxide (DMSO) at $\mathrm{pH}$ 2.00. No antimicrobial effect was observed against $S$. aureus (Gram-positive) and E. coli (Gram-negative), and no antifungal effect against Aspergillus niger, for the samples analyzed, as there was no formation of inhibition halos (Fig. $5)$.

Table 3

Antioxidant capacity determined by the free radical 2,2-diphenyl-1-picryl-hydrazyl (DPPH) method for different concentrations of Kraft lignin microparticles

\begin{tabular}{cccc}
\hline Kraft lignin microparticles & \multicolumn{3}{c}{ Radical scavenging activity (\%) after solution resting time (min) } \\
\cline { 2 - 4 } concentrations (\%) & $0 \mathrm{~min}$ & $30 \mathrm{~min}$ & $60 \mathrm{~min}$ \\
\hline 1 & $42.93 \pm 0.37^{\mathrm{a}}$ & $41.41 \pm 0.64^{\mathrm{a}}$ & $40.77 \pm 1.51^{\mathrm{a}}$ \\
2 & $42.71 \pm 4.11^{\mathrm{a}}$ & $46.83 \pm 2.67^{\mathrm{ab}}$ & $48.96 \pm 3.08^{\mathrm{ab}}$ \\
4 & $48.82 \pm 3.46^{\mathrm{a}}$ & $53.46 \pm 4.44^{\mathrm{b}}$ & $50.86 \pm 5.64^{\mathrm{a}}$ \\
6 & $64.09 \pm 1.91^{\mathrm{b}}$ & $74.45 \pm 4.06^{\mathrm{c}}$ & $55.42 \pm 4.36^{\mathrm{b}}$ \\
\hline
\end{tabular}

Each value is the average of the repetitions with the standard deviation; Means followed by equal letters in the column do not differ statistically from each other, by the Tukey's test at 5\% 


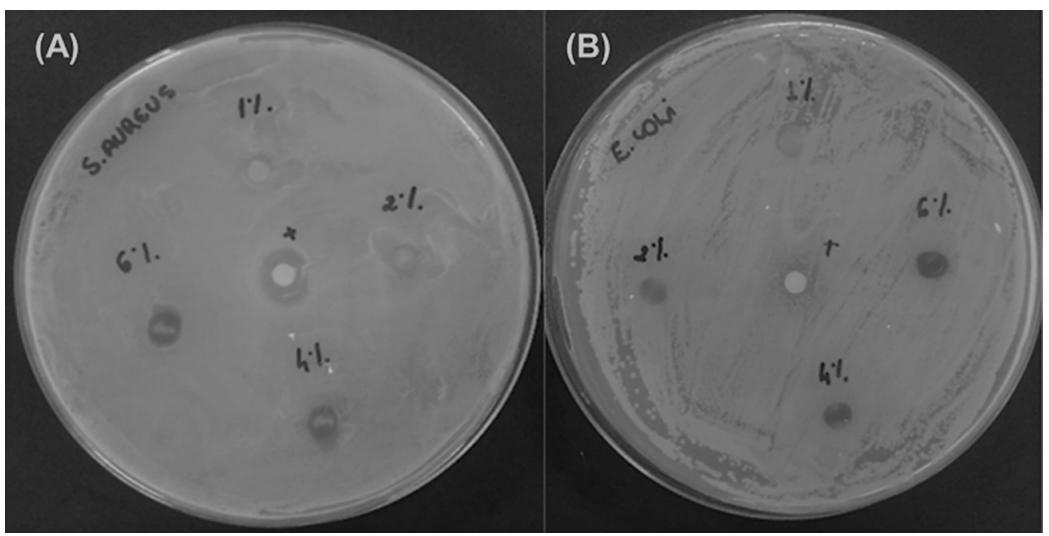

Figure 5: Microbiological assay of the Kraft lignin microparticle solution in DMSO in concentrations of 1\%, 2\%, 4\% and $6 \%$ against Gram-positive (S. aureus (A)) and Gram-negative (E. coli (B)) bacteria

However, several studies have shown different results for various types of lignin. Dong et al..$^{28}$ and Dong et $a l .{ }^{8}$ evaluated alkaline lignin with low sulfur content and reported antimicrobial activities of the extracts against Gram-positive bacteria (Listeria monocytogenes and Staphylococcus aureus) and yeasts (Candida lipolytica), but no effect against Gram-negative bacteria (Escherichia coli O157: H7 and Salmonella enteritidis) or bacteriophage MS2.

Klein $e t a l .^{29}$ evaluated the effect of Kraft lignin against Gram-positive bacteria ( $S$. aureus) under different $\mathrm{pH}$ conditions (2 to 5), and obtained a satisfactory result against the microorganism mainly at $\mathrm{pH}$ 5. Kaur, Uppal and Sharma ${ }^{9}$ evaluated the antimicrobial activity of chemically modified lignin (by acetylation, epoxidation and hydroxymethylation reactions), and observed that epoxy lignin was more effective against Bacillus sp. and Klebsiella sp., among all the unmodified and modified lignins.

In general, the phenolic compounds with functional groups containing oxygen (such as hydroxyl, carbonyl and ester groups) in the side chain have a lower inhibitory effect, when compared to those with double bonds and methyl groups, which increase the biocidal effect of the phenolic compounds. The structure of the side chain and the nature of the functional groups of the phenolic compounds are the main determinants of the antimicrobial effect of lignin. ${ }^{14}$

Thus, in the present study, it is possible that the modification of the raw material led to changes in the availability of the active functional groups, which exert an inhibitory effect against microorganisms. In addition, the complex structure of lignin may be another factor limiting the availability of functional groups.

\section{CONCLUSION}

In the present work, Kraft lignin microparticles were successfully prepared by ball milling and their properties were compared with those of initial Kraft lignin. The findings revealed that the mechanical treatment promoted the reduction of particle size, the microparticles obtained had greater homogeneity and good thermal resistance. However, they showed greater instability, with a greater tendency to agglomerate. In this study, no antimicrobial effect was found for the lignin and the lignin microparticles against the bacteria analyzed. Nonetheless, the particles showed antioxidant potential and can be used in the development of active packaging to prevent oxidation reactions in food.

ACKNOWLEDGMENTS: The authors would like to thank the Research Support Foundation of the State of Minas Gerais (FAPEMIG); the National Council for Scientific and Technological Development $(\mathrm{CNPq})$; and the Coordination of Improvement of Higher Level Personnel (CAPES) for financial support and scholarships. The authors also thank the Laboratory of Electron Microscopy and Analysis of Ultrastructural Federal University of Lavras, (http://www.prp.ufla.br/labs/microscopiaeletronic a/) and Finep, Fapemig, CNPq and Capes for providing the equipment and technical support for experiments involving electron microscopy. The authors would like to thank all the employees of Embrapa Instrumentation for helpful assistance; 
and the Federal University of Viçosa (Rio Paranaíba Campus) for the provision of equipment and technical support for experiments.

\section{REFERENCES}

1 J. Chen, C. Liu, S. Wu, J. Liang and M. Lei, RSC Adv., $\quad$ 6, $\quad 107970 \quad$ (2016), https://doi.org/10.1039/c6ra18923g

2 J. L. Espinoza-Acosta, P. I. Torres-Chávez, B. Ramírez-Wong, C. M. López-Saiz and B. MontañoLeyva, BioResources, 11, 5452 (2016), https://doi.org/10.15376/biores.11.2.Espinoza_Acosta

3 S. Sutradhar, K. M. Yasin Arafat, J. Nayeem and M. Sarwar Jahan, Cellulose Chem. Technol., 54, 463 (2020),

https://doi.org/10.35812/CelluloseChemTechnol.2020. 54.47

4 W. Gao and P. Fatehi, Can. J. Chem. Eng., 9, 2827 (2019), https://doi.org/10.1002/cjce.23620

5 J. Chen, F. Shen, G. Lyu, G. Yang, N. Lu et al., Cellulose Chem. Technol., 52, 371 (2018), https://www.cellulosechemtechnol.ro/

6 X. Dong, M. Dong, Y. Lu, A. Turley, T. Jin et al., Ind. Crop. Prod., 34, $1629 \quad$ (2011), https://doi.org/10.1016/j.indcrop.2011.06.002

7 W. Yang, J. S. Owczarek, E. Fortunati, M. Kozanecki, A. Mazzaglia et al., Ind. Crop. Prod., 94, 800

http://dx.doi.org/10.1016/j.indcrop.2016.09.061

8 R. A. C. Gomide, A. C. S. Oliveira, D. A. C. Rodrigues, C. R. Oliveira, O. B. G. Assis et al., J. Polym. Environ., 28, 1 (2020), https://doi.org/10.1007/s10924-020-01685-z

R. Kaur, S. K. Uppal and P. Sharma, Sugar Tech., 19, 675 (2017), https://doi.org/10.1007/s12355-0170513-y

10 A. Tribot, G. Amer, M. A. Alio, H. Baynast, C. Delattre et al., Eur. Polym. J., 112, 228 (2019), https://doi.org/10.1016/j.eurpolymj.2019.01.007

11 Y. Ge, Q. Wei and Z. Li, BioResources, 9, 6699 (2014), https://doi.org/10.15376/biores.9.4.6699-6706

12 M. Lievonen, J. J. Valle-Delgado, M. Mattinen, E.L. Hult, K. Lintinen et al., Green Chem., 18, 1416 (2016), https://doi.org/10.1039/c5gc01436k

13 A. Rangan, M. V. Manchiganti, R. M. Thilaividankan, S. G. Kestur and R. Menon, Ind. Crop. Prod., 103, 152 (2017), http://dx.doi.org/10.1016/j.indcrop.2017.03.037

14 W. Yang, E. Fortunati, D. Gao, G. M. Balestra, G. Giovanale et al., ACS Sustain. Chem. Eng., 6, 3502 (2018),

https://doi.org/10.1021/acssuschemeng.7b03782
15 S. S. Nair, S. Sharma, Y. Pu, Q. Sun, S. Pan et al., ChemSusChem, 7, $3513 \quad$ (2014), https://doi.org/10.1002/cssc.201402314

16 I. A. Gilca, V. I. Popa and C. Crestini, Ultrason. Sonochem., $\quad \mathbf{2 3}, \quad 369 \quad$ (2015), http://dx.doi.org/10.1016/j.ultsonch.2014.08.021

17 S. H. D. Hulleman, M. G. Kalisvaart, F. H. P. Janssen, H. Feil and J. F. G. Vliegenthart, Carbohyd. Polym., 39, 351 (1999), https://doi.org/10.1016/S01448617(99)00024-7

18 Y. Byun, Y. T. Kim and S. Whiteside, J. Food Eng., $\quad \mathbf{1 0 0}, \quad 239 \quad$ (2010), https://doi.org/10.1016/j.jfoodeng.2010.04.005

19 National Committee for Clinical Laboratory Standards. Performance Standards for Antimicrobial Disk Susceptibility Tests; Approved Standard. NCCLS Document M2-A8. Wayne, PA: National Committee for Clinical Laboratory Standards, 2003

20 National Committee for Clinical Laboratory Standards. Reference Methods for Broth Dilution Antifungal Susceptibility Testing of Filamentous Fungi; Approved Standards. NCCLS Document M38 $\square$ A. Wayne, PA: National Committee for Clinical Laboratory Standards, 2002

21 J. Luo, J. Genco, B. Cole and R. Fort, BioResources, $\quad$ 6, $4566 \quad$ (2011), https://doi.org/10.15376/biores.6.4.4566-4593

22 L. Pandochi, PhD Thesis, Araraquara, SP, Universidade Estadual Paulista, Instituto de Química, 2009

23 Z.-H. Liu, N. Hao, S. Shinde, Y. Pu, X. Kang et al., Green Chem., 21, $245 \quad$ (2019), https://doi.org/10.1039/c8gc03290d

24 J. Zhou, J. Tong, X. Su and L. Ren, Int. J. Biol. Macromol., 91, $1186 \quad$ (2016), http://dx.doi.org/10.1016/j.ijbiomac.2016.06.082

25 A. García, A. Toledano, M. A. Andrés and J. Labidi, Process Biochem., 45, 935 (2010), https://doi.org/10.1016/j.procbio.2010.02.015

26 M. R. V. Bertolo, L. B. B. Paiva, V. M. Nascimento, C. A. Gandin, M. O. Neto et al., Ind. Crop. Prod., 140, $111591 \quad$ (2019), https://doi.org/10.1016/j.indcrop.2019.111591

27 A. Garcia, M. G. Alriols, G. Spigno and J. Labidi, Biochem. Eng. J., 67, $173 \quad$ (2012), http://dx.doi.org/10.1016/j.bej.2012.06.013

28 L. Dong, L. Yin, Q. Xia, X. Liu, X.-Q. Gong et al., Catal. Sci. Technol., 8, $735 \quad$ (2018), https://doi.org/10.1039/c7cy02014g

29 S. E. Klein, A. Alzagameem, J. Rumpf, I. Korte, J. Kreyenschmidt et al., Coatings, 9, 44 (2019), https://doi.org/10.3390/coatings9080494 